\title{
Does 4G Technology Trigger the S-commerce Era Coming? Evidence from Taiwanese ICT Market.
}

\author{
${ }^{1}$ Ming-Yuan Hsieh Assistant Professor \\ Department of International Business \\ National Taichung University of Education \\ Taichung City, Taiwan (R.O.C.) \\ e-mail: uscpawisely@hotmail.com \\ ${ }^{3}$ Kuang-Yu Huang Fully Professor \\ Department of Information Management \\ Ling Tung University \\ Taichung City, Taiwan (R.O.C.) \\ e-mail: kyhuang@teamail.ltu.edu.tw
}

\author{
${ }^{2}$ Chih-Cheng Huang Assistant Professor \\ Department of Leisure \& Recreation \\ National Formosa University \\ Yunlin City, Taiwan (R.O.C.) \\ e-mail: cchuang@nfu.edu.tw \\ ${ }^{4}$ Hsiu-Wei Hsu Project Manager \\ Division of Continuing \\ National Taichung University of Education \\ Yunlin City, Taiwan (R.O.C.) \\ e-mail: ceoweaxp@gm.ntcu.edu.tw
}

\begin{abstract}
In reviewing of the generalization of wireless technology in the variously relative information and communication technology (ICT) industries, this research systematically explore the potential determinants of the fourth generation (4G) technology to cross-analyze the drivers of the smart-commerce (S-commerce) era forthcoming through the comprehensive measurements of the hierarchical analytical network process (ANP) resulted from the multiple criteria decision making (MCDM) methodology by gathering of the Taiwanese ICT market surveyed data. The most contribution is that "the 4G technology probably trigger the Smartcommerce (S-commerce) era coming. (4GPYTSEC)" that means the S-commerce is still the developed mainstream in the variously relative ICT industries according to the some restricted factors, such as technological development limitation, government political prohibition, users' operational restrains.
\end{abstract}

Keywords- information and communication technology (ICT); the fourth generation (4G); the hierarchical analytical network process (ANP); Smart-commerce (S-commerce)

\section{INTRODUCTION}

At present, on account of the rapid development and various employment consisted of the web-portals, such as Yahoo, Google and etc., the virtually social communities, such as Twitter, Facebook and etc., and the cross-applied apparatuses, such as smart phones, tablets, GPS and etc., [1], of wireless information technology, the information telecommunication technology ("ICT") has comprehensively pioneered and the ICT comprised of computers software and hardware technology, consumer electronic ("3C") technology, wired television sets technology, mobile phones ("MP") technology and global position systems ("GPS) technology, have been integrated the various applications in order to create more comprehensive IT features and innovative technologies [2]. Specifically, the mobile online activities of the extensive ICT users' have evolved from surfing one-way in unitary position to interactively surfing and two-way coding in multiple location in order to successfully satisfy user's need for faster online processing times [3] based on the high-speed bandwidth and wireless transmission technologies into the information technology ("IT") and the information telecommunication technology ("ICT") industries. In addition, in terms of a series of the transmitted evolution of the ICT, there are current achieving the four generation consisted of the first generation (" $1 G$ "), second generation (" $2 G$ "), third generation (" $3 \mathrm{G}$ ") and fourth generation (" $4 \mathrm{G}$ ") and at present, the majority of developed countries have been reached in the 4G era. Subsequently, according to the recent literatures in the digital and virtual business field, the traditional digital and virtual business has evolved into the latest period from the original electronic commerce ("e-commerce"), the mediate mobile-commerce ("m-commerce") to the current smart-commerce ("scommerce"). In consideration of the interplays between the ICT technology and digital commerce, the relationship between the $4 \mathrm{G}$ and s-commerce has been the most crucial topic for the present relative researches because most of academic researchers, empirical senior managers and political government have desired to acknowledge the real core-value of the s-commerce in order to create the most benefits in the each diversified level of society nowadays. Consequently, this research attempts to essentially employ the analytical network process ("ANP") of the multiple criteria decision making ("MCDM") methodology to construct the more effectively and hierarchically weighted evaluated model to efficiently and systematically crossanalyze the most critical interplays and characteristics among each assessable criteria in order to discovery the direct solution for the research topic: "Does 4G Technology Trigger the S-commerce Era Coming?"

\section{LITERATURE REVIEW}

This research attempts to utilize the hierarchical 
weighted evaluated ANP model of the MCDM methodology to assess the professional weighted comments from their questionnaires through the cross-employment of the Delphi and brainstorm approaches under the comprehensive, limited-resource and difficult-decision circumstances. Hence, this section is going to systematically concentrate on the ANP model of the MCDM methodology.

[4] further pioneered the ANP consisted of the positive reciprocal matrix and supermatrix, to break through this limited hypothesis in order to deal with more complex hierarchical analysis for the various kinds of research issues. Subsequently, [5] further pointed out the typical measurements process that overall related-influenced factors are categorized into four groups and then, based on the patterns of the ANP evaluation model, these relatedimpacted factor-groups are decomposed as four assessment hierarchies [6]. In succession, on an account of the ANP evaluated statistic measurements, the priority vector $\mathrm{w}$ (eigenvector) of the assessable criteria were calculated for the potential candidate of the topic after the pairwise comparisons have been established. In particular, [7] organized the two-stage algorithm as described in equations as $R w=$ $\lambda_{\max } w$ and

$$
w_{i}=\sum_{j=1}^{m}\left(\frac{R i j}{\sum_{j=1}^{m} R i j}\right) / m
$$

In each pairwise comparison between each criterion, the consistency of compared criteria is going to match transitivity in order to achieve the representativeness of the expert's collections. The Consistency Index ("C.I.", C.I. $\left.=\left(\lambda_{\max }-n\right) /(n-1)\right)$ which is exactly considered in each pairwise matrix and the Consistency Ratio ("C.R.", $C . R .=$ C .I./ R.I. ) which is estimated with C.I. and Random Index ("R.I") acquired from the statistic table of random index figure, are expressed in equation (2). The most important assessable and acceptable regulation is that the evaluated numbers of C.R. and C.I. both are definitely necessary smaller than 0.1 .

\section{RESEARCH DESIGN}

With reference to the employment of the hierarchical weighted ANP approach, the collection of surveyed questionnaires are collected from the professional experts' the opinions from the three brief aspects comprised of the experienced ICT users, the empirical ICT senior managers and the academic scholars [8] in order to deal with retrospective sectional analysis of the hierarchical relations for organizing the assessed hierarchy by testifying each the related-impacted criterion from collecting the potential and influenced elements.

\section{A. Research Framework}

With respect to the research framework beyond the comprehensive overlook of the relative literatures, the research design framework is systematically described in Fig.1.

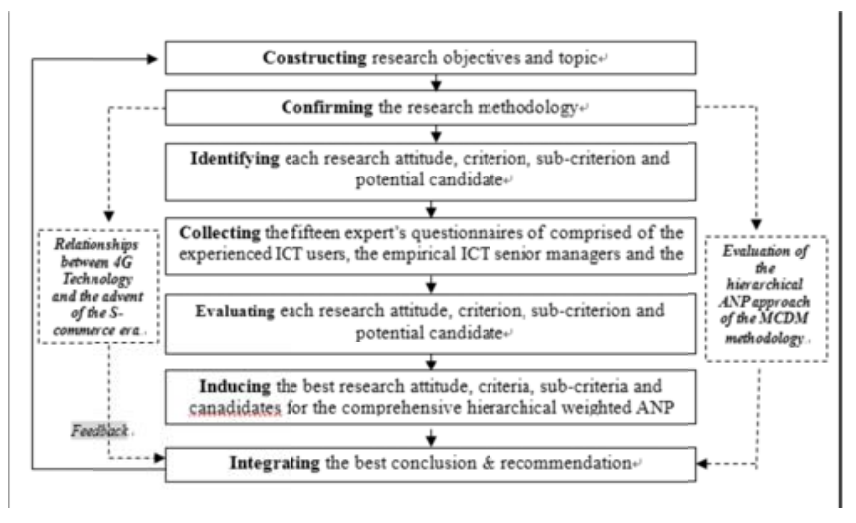

Figure 1. Research Framework.

\section{B. Questionnaire Scale}

In consideration of the representativeness of the efficient methodology through establishing, comparing weights principle, evaluating criteria, and estimating positive reciprocal matrix and supermatrix, questionnaire scale have to construct the five level structure related interdependence and importance from equal important (1) to extreme important (5) resulted from the Lekert's concept.

\section{Collection Entire of Survey Data}

In order to increase the research validity, reliability and representativeness, the three brief aspects comprised of the experienced ICT users, the empirical ICT senior managers and the academic scholars according to the specific characteristics of the hierarchical weighted ANP approach. The collection entire of survey data were gathered and from the fifteen experts' questionnaires and these experts cover the five experienced users, the five empirical senior managers as well as the five academic scholars in the relative IT and ICT fields.

\section{Research Assessable Criteria}

This research comprehensively integrates the most potential influenced factors of the $4 \mathrm{G}$ to identify as each attitudes of analytic aspect covered ICT experienced users' perspective, ICT empirical senior managers' aspect and ICT Academic scholars' aspect; assessable criteria of the ICT's specific characteristics consisted of ICT-technology characteristics ("ICTC"), virtual social community characteristics ("VSC"), location GPS characteristics ("LGC") and mobile service characteristics ("MSC") for inducing the best solution among three briefly selected candidates comprised of the $4 \mathrm{G}$ technology positively trigger the S-commerce era coming ("4GPTSEC"), the 4G technology probably trigger the S-commerce era coming. ("4GPYTSEC") and the 4G technology negatively trigger the S-commerce era coming. ("4GNTSEC") for the research topic. Further, the sub-criteria are resulted from the keytechnologies of the ICT in the 4G [9] as well as categorized into the four assessable criteria. Hence, there are 1). the ICTC comprehends (1) Behavior Targeting ("BT") [10], (2) Web 2.0 ("W2") [11], (3) Web 3.0 
(“W3”) [12], (4) Keyword Search Engine (“KSE”) [13], (5) Augmented Reality Function ("ARF") [14] and (6) Virtual cloud computing ("VCC") [15]; 2). the VSC covers (1) Rich Media ("RM") [16], (2) Really Simple Syndication ("RSS") [17] and (3) Social Community Integration ("SCI") [18]; 3). the LGC: (1) Wideget function ("WF") [19], (2) Location Based Service ("LPS") [20] and (3) Real-time Direct Messages ("RDM") and 4). the MSC: (1) Alternate Reality Games (“ARG”), (2) Application Programming Interface ("API") and (3) Multiple Mobile APP ("MM-APP"). The entire appraised attitudes, assessable criteria and sub-criteria and evaluated selected candidates are cross-employ to deal with retrospective sectional analysis of the hierarchical relations for organizing the assessed hierarchy by testifying each the related-impacted criterion from collecting the potential and influenced elements.

\section{E. Research Evaluated Hierarch}

Beyond the completions of the research design, framework and assessable criteria, the research evaluated hierarch has been pioneered as follows in Fig. 2, according to the specific characteristics of the hierarchical weighted ANP approach [25] in order systematically to deal with the fifteen experts' questionnaire comments as well as synthetically to achieve the essential concept of this research topic: "Does 4G Technology Trigger the S-commerce Era Coming? Evidence from Taiwanese ICT Market."

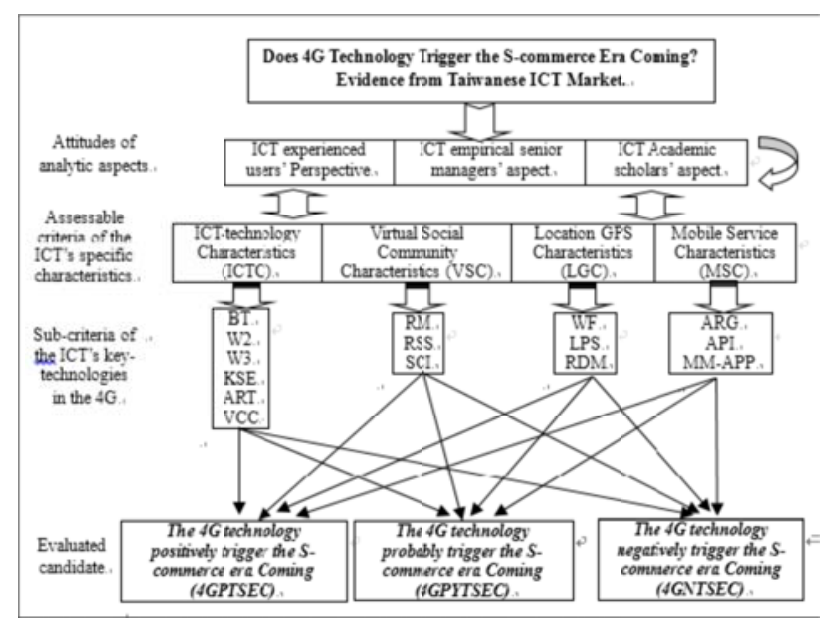

Figure 2. Research Eavlated Hierarch

\section{MEASURED RESULTS}

Beyond the completed construction of the hierarchically effective and efficient weighted ANP model, the synthetic weighted index ("SWI") of the three potential solutions for the research topics have been measured in Table 1.
TABLE I. MEASURED RESULTS

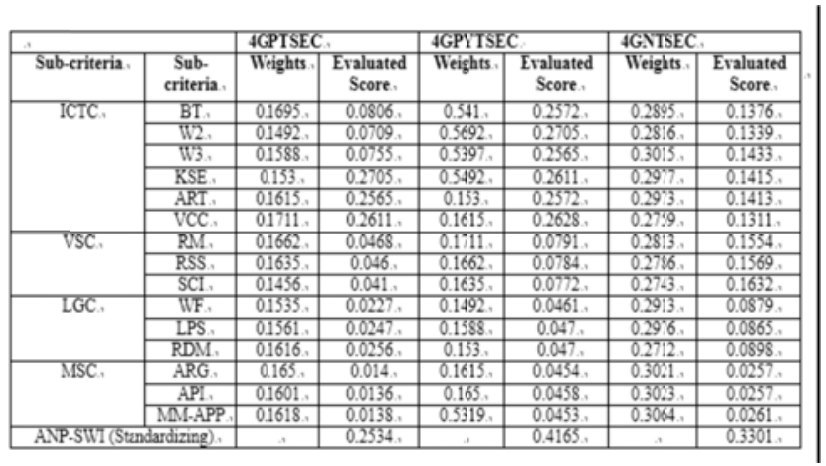

Consequently, in terms of the measurements and calculated consequences Table 1 , the highest SWI is 0.4165 as well as locates at "the $4 \mathrm{G}$ technology probably trigger the S-commerce era coming. (4GPYTSEC).

\section{DISCUSSION AND CONCLUSION}

In particular, with respect to the generalization of wireless technology in the variously relative information and communication technology (ICT) industries, this research systematically explore the potential determinants of the fourth generation $(4 \mathrm{G})$ technology to cross-analyze the drivers of the smart-commerce (S-commerce) era forthcoming through the comprehensive measurements of the hierarchical analytical network process (ANP) resulted from the multiple criteria decision making (MCDM) methodology by gathering of the Taiwanese ICT market surveyed data. The most contribution is that "the 4G technology probably trigger the S-commerce era coming. (4GPYTSEC)" that means the S-commerce is still the developed mainstream in the variously relative ICT industries according to the some restricted factors, such as technological development limitation, government political prohibition, users' operational restrains. Nevertheless, this research also effectively expands the author's past researches comprised of relationships between the developed tendency of the ICT technology and the wireless speedy technology as well as the human behaviors transmission and so on.

\section{REFERENCES}

[1] T. L. Saaty, "Decision Making with Dependence and Feedback: The Analytic Network Process", RWS Publications, Pittsburgh, PA, 1996.

[2] T. L. Saaty, "Multi-criteria decision making: the analytic hierarchy process", RWS Publications, Pittsburgh, PA, 1998.

[3] E. Deutskens, de Ruyter, K. and M. Wetzels, "An assessment of equivalence between online and mail surveys in service research", Journal of Service Research, vol. 8, pp. 346-355, 2006.

[4] L. Egghe, "The Hirsch index and related impact measures", Annual Review of Information Science and Technology, vol. 44, pp. 65-114., 2010.

[5] M. Hassenzahl and N. Tractinsky, "User experience: a research agenda", Behaviour and Information Technology, vol. 25, pp. 91-97, 2006.

[6] M,. Hassenzahl and D. Ullrich, "To do or not to do? Differences in user experience and retrospective judgments depending on the 
presence or absence of instrumental goals", Interacting with Computers, vol. 19, pp. 429-437, 2007.

[7] M.E. Kipp, "Complementary or discrete contexts in online indexing? A comparison of user, creator, and intermediary keywords", Canadian Journal of Information and Library Science, vol. 29, 419- 436, 2006.

[8] H. Lu and K.L. Hsiao, "Gender differences in reasons for frequent blog posting”, Online Information Review, vol. 33, pp. 135-156, 2009.

[9] D.R. Millen, Feinberg, J. and B. Kerr , "Dogar: social bookmarking in the enterprise", Proceedings of the Conference on Computer Human Interaction, ACM Press, New York, NY, pp. 111-120, 2006.

[10] R. Pak, Pautz, S. and R. Iden, "Information organization and retrieval: an assessment of taxonomical and tagging systems", Cognitive Technology, vol. 12, pp. 31-44, 2007.

[11] I. Qureshi and D. Compeau, "Assessing between-group differences in information systems research: a comparison of covariance- and component-based SEM", MIS Quarterly, vol. 33, pp. 199-216, 2009 .

[12] M.J. Sanchez-Franco and J.L. Roldan, "Expressive aesthetics to ease perceived community support: exploring personal innovativeness and routinised behaviour as moderators in Tuenti", Computers in Human Behavior,vol. 26(6), pp. 1445-1457, 2010.

[13] J. Sauer and A. Sonderegger, "The influence of prototype fidelity and aesthetics of design in usability tests: effects on user behaviour, subjective evaluation and emotion", Applied Ergonomics, vol. 40, pp. 670-677, 2009 .

[14] C. Styles, "How web 2.0 will change history - possible futures for websites of the National Archives of Australia!", available at: $<$ ttp://catherinestyles.files.wordpress.com/2006/08/web20history1. pdf $>$, 2006, Febuary.

[15] Tractinsky, et al., "Evaluating the consistency of immediate aesthetic perceptions of webpages", International Journal of Human-Computer Studies, vol. 64, pp. 1971-1983, 2006.

[16] Y.J. Wang, Hernandez, M.D. and M.S. Minor, "Web aesthetics effects on perceived online service quality and satisfaction in an e-tail environment: the moderating role of purchase task", Journal of Business Research, vol. 63, 935-942, 2009.

[17] D. Wolfram and H.A. Olson, "A method for comparing large-scale inter-indexer consistency using IR modeling", Proceedings of the 35th Annual Canadian Association for Information Science, available at: www.cais-adsi.ca/2007/wolfram_2007.pdf , 2007, June.

[18] L. Zeng and G. Salvendy, "How creative is your website?", Proceedings of the 2nd International Conference on Applied Human Factors and Ergonomics (AEI 2008), Las Vegas, NV, pp. 1-10, 2008.

[19] L. Zeng, Salvendy, G. and M. Zhang, "Factor structure of website creativity", Computers in Human Behavior, vol. 25, 568-77, 2009.

[20] P. Zhang and G.M. Von-Dran, "Satisfiers and dissatisfiers: a twofactor model for website design and evaluation", Journal of the American Society for Information Science, vol. 51, pp. 1253-1268, 2000 . 